\title{
Simulasi Sistem Monitoring Link Metro Ethernet (ME) di PT Indosat Ooredoo Medan dengan Metode Doppler
}

\author{
Mhd Ramadhan Nainggolan, Pristiwanto \\ Prodi Teknik Informatika, STMIK Budi Darma, Medan, Indonesia \\ Email: mhdramadhan06@gmail.com \\ Submitted 08-05-2020; Accepted 01-06-2020; Published 14-06-2020
}

\begin{abstract}
Abstrak
Perkembangan Teknologi saat ini sudah begitu pesat, monitoring jaringan komputer menjadi suatu hal yang sangat di butuhkan. Koneksi jaringan komputer merupakan suatu hal yang mendasar dalam jaringan komputer tidak dapat digunakan. Begitu juga untuk kerja jaringan Metro Ethenet, Bila suatu parameter itu bermasalah maka kualitas jaringan tersebut akan berkurang dan Sering terjadi lamanya monitoring Metro ethernet dan akses untuk report laporan ME jadi terganggu. Tugas Akhir ini saya akan membahas bagaimana Sistem Simulasi monitoring Link Metro Ethernet di PT Indosat Ooredoo dengan metode doppler untuk mengetahui status Link Pada Metro Ethernet menggunakan topologi tree karena Cuma mensimulasikan 3 Metro Ethernet selain itu juga akan membahas kinerja Metro Ethernet yaitu menganalisa penerapan simulasi, dan status Link Metro Ethernet. Metro ethernet merupakan salah satu solusi teknologi untuk High End Market (HEM) dalam memberikan solusi terintegrasi untuk layanan voice, data dan video. Metro ethernet network memiliki karakteristi. Berdasarkan permasalahan di atas maka dibutuhkan sistem untuk simulasi monitoring Link Metro Ethernet di PT.Indosat Ooredoo untuk mendapatkan hasil yang lebih baik dari sistem sebelumnya.
\end{abstract}

Kata Kunci: Simulasi, Monitoring, Metro Ethenet, Metode Doppler.

\begin{abstract}
Current technological developments have been so rapid, monitoring computer networks has become a very necessary thing. Computer network connection is a fundamental thing in a computer network that cannot be used. Likewise for the Metro Ethenet network work, If a parameter is problematic then the quality of the network will be reduced and Frequently occurs the duration of Metro ethernet monitoring and access to the report report ME becomes disrupted. This Final Project I will discuss how the Metro Ethernet Link Monitoring Simulation System in PT Indosat Ooredoo with the doppler method to determine the status of the Link on Metro Ethernet uses tree topology because it only simulates 3 Metro Ethernet and also discusses Metro Ethernet performance, which analyzes simulation applications, and Metro Ethernet Link status. Metro Ethernet is one of the technological solutions for High End Market (HEM) in providing integrated solutions for voice, data and video services. Metro Ethernet network has characteristics. Based on the above problems, a system for Metro Ethernet Link monitoring simulation is needed at Indosat Ooredoo to get better results than the previous system.
\end{abstract}

Keywords: Simulation, Monitoring, Metro Ethernet, Doppler Method.

\section{PENDAHULUAN}

Perkembangan teknologi telekomunikasi sudah sangat maju dengan pesat. Kemajuan yang telah dirasakan sejak adanya penemuan telegraf dan telepon di tahun 1800-an hingga sekarang di era millenium ini sudah sangat maju. PT. Indosat Ooredoo merupakan salah satu perusahaan terbesar di indonesia yang menyediakan layanan penyedia jasa telekomunikasi dan jaringan telekomunikasi di Indonesia.Perusahaan ini menawarkan saluran komunikasi untuk pengguna telepon genggam dengan pilihan pra bayar maupun pascabayar, teknologi seluler. Perusahaan ini juga memiki banyak bts khususnya di daerah perkotaan dan perusahaan ini memiliki team untuk memonitoring status teknologi Global System for Mobile (GSM), teknologi seluler berbasis Code Division Multiple Access (CDMA), Fiber Optic (FO). Dan Metro Ethernet (ME). Baik di lokal maupun di pusat.

Simulasi adalah suatu proses peniruan dari sesuatu yang nyata beserta keadaan sekelilingnya (state of affairs). Aksi melakukan simulasi ini secara umum menggambarkan sifat-sifat karakteristik kunci dari kelakuan sistem fisik atau sistem yang abstrak tertentu. Teknik simulasi adalah teknik untuk merepresentasikan atau meniru kondisi real (suatu sistem nyata) dalam bentuk bilangan dan simbol (dengan memanfaatkan program komputer), sehingga menjadi mudah untuk dipelajari. Keuntungan menerapkan simulasi dalam proses rekayasa produk (dikenal dengan istilah CAE, Computer Aided Engineering) jelas, anda tidak perlu membuat cetak biru di tahap awal, cukup membuat disain yang detail. Langkah selanjutnya adalah melakukan berbagai eksperimen secara virtual terhadap desain tersebut[1].

Monitoring Metro Ethernet adalah alat untuk mengawasi kinerja perangkat dari jarak jauh. Perangkat yang di awasi mudah diatur dan bahkan lebih mudah digunakan. Opsi yang paling mudah dan efisien di pasar adalah program Web. Semua fungsi pemancar dapat diakses baik oleh PC atau remote control. Server atau alamat IP yang dapat ditentukan pengguna dapat diakses oleh PC lokal atau koneksi Ethernet. Pemancar tersedia dengan server web tertanam sehingga tidak ada perangkat lunak tambahan untuk dimuat. Dan memiliki beberapa opsi koneksi agar sesuai dengan kebutuhan pekerjaan yang ada di perusahaan tersebut. Link (juga hyperlink) adalah sebuah acuan dalam dokumen hiperteks (hypertext) ke dokumen yang lain atau sumber lain. Seperti halnya suatu kutipan di dalam literatur. Dikombinasikan dengan sebuah jaringan data dan sesuai dengan protokol akses, sebuah komputer dapat diminta untuk memperoleh sumber yang direferensik[2].

Permasalahan yang terjadi di Indosat Ooredoo ada beberapa kelemahan dalam memonitoring (pengawasan perangkat ME Untuk pelanggan). Yaitu Komplen Pelanggan atau pengguna yang mengeluhkan mengenai seringnya jaringan indosat yang lambat dan tim monitoring lama dalam pengecekan link untuk status link Metro baik up ataupun Down karena terkenala bandwidht. Komplin pelanggan yang sering yaitu daerah Cempaka, Komplek astra dan Jamin ginting. 
Berdasarkan Permasalahan diatas maka penulis berinisiatif untuk membuat simulasi sistem monitoring Link ME menggunakan metode doppler agar pekerjaan karyawan dan team monitoring dalam mengawasi perangkat tersebut lebih mudah,simple dan tidak memakan waktu yang lama dalam pengecekan link Metro ethernet dan pembuatan report global.

\section{METODE PENELITIAN}

\subsection{Simulasi}

Simulasi adalah suatu proses peniruan dari sesuatu yang nyata beserta keadaan sekelilingnya (state of affairs). Aksi melakukan simulasi ini secara umum menggambarkan sifat-sifat karakteristik kunci dari kelakuan sistem fisik atau sistem yang abstrak tertentu. Simulasi merupakan proses aplikasi membangun model dari sistem nyata atau usulan sistem, melakukan eksperimen dengan model tersebut untuk menjelaskan perilaku sistem,mempelajari kinerja sistem atau untuk membangun sistem baru sesuai dengan kinerja yang diinginkan.[2]

\subsection{Monitoring}

Monitoring adalah Adalah Aktifitas yang di tujukan untuk memberikan informasi tentang sebab dan akibat dari suatu kejadian yang sedang dilaksanakan.[3]

Monitoring mempunyai empat fungsi, yaitu:

1. Ketaatan (compliance).

Monitoring menentukan apakah tindakan administrator, staf dan semua yang terlibat mengikuti standar dan prosedur yang telah ditetapkan.

2. Pemeriksaan (auditing).

Monitoring menetapkan apakah sumber dan layanan yang diperuntukkanbagi pihak tertentu bagi pihak tertentu (target) telah mencapai mereka

3. Laporan (accounting).

Monitoring menghasilkan informasi yang membantu "menghitung" hasil perubahan sosial dan masyarakat sebagai akibat implementasi kebijaksanaan sesudah periode waktu tertentu.

4. Penjelasan (explanation).

Monitoring menghasilkan informasi yang membantu menjelaskan bagaimana akibat kebijaksanaan dan mengapa antara perencanaan dan pelaksanaannya tidak cocok.

\subsection{Link}

Link (juga hyperlink) adalah sebuah acuan dalam dokumen hiperteks (hypertext) ke dokumen yang lain atau sumber lain. Seperti halnya suatu kutipan di dalam literatur. Dikombinasikan dengan sebuah jaringan data dan sesuai dengan protokol akses, sebuah komputer dapat diminta untuk memperoleh sumber yang direferensikan.[4]. Tujuan dibuatnya link adalah sebagai jalan pintas atau shortcut menuju halaman atau website lain. Link dapat berupa tulisan ataupun gambar.

\subsection{ME (Metro Ethernet)}

Metro ethernet merupakan salah satu solusi teknologi untuk High End Market (HEM) dalam memberikan solusi terintegrasi untuk layanan voice, data dan video. [5]

Metro ethernet network memiliki karakteristik antara lain :

1. Data transmisi melewati transmitter (pemancar) dan receiver (penerima) melalui media transmisi.

2. Teknologi IP optik berbasis Synchronous Digital Hierarchy atau Ethernet.

a. Dapat mengakomodasi layanan berupa voice, data, high speed internet acces dan video.

b. Kecepatan tinggi hingga Gigabit Ethernet/1000Mbps.

Jaringan Metro Ethernet, secara harfiah berarti jaringan komunikasi data yang berskala metro (skala untuk menjangkau satu kota besar seperti Jakarta) dengan menggunakan teknologi Ethernet sebagai protokol transportasi datanya. Begitu pula arti sebenarnya, teknologi Metro Ethernet merupakan salah satu perkembangan dari teknologi Ethernet yang dapat menempuh jarak yang luas berskala perkotaan dengan dilengkapi berbagai fitur yang seperti terdapat pada jaringan Ethernet umumnya. Sehingga jaringan yang berskala metro dapat dibentuk dengan menggunakan teknologi Ethernet biasa.

\subsection{Metode Doppler}

Efek Doppler adalah Perubahan frequency suatu gelombang Sumber pada seorang penerima yang sedang bergerak relative terhadap sumber. Efek Doppler dinamakan berdasarkan seorang ilmuwan Autria, Christian Doppler, yang pertama kali menjelaskan fenomena tersebut pada tahun 1842. Efek Doppler dapat ditemukan pada segala jenis gelombang, seperti gelombang Sumber Udara, gelombang Sumber Angin, dan lain-lain.[6]

Jika (penerima) sedang diam dan sumber Power yang juga diam (Netral), maka sumber yang diterima akan memiliki frekuensi yang sama dengan sumber power. Namun, Efek Doppler akan terjadi saat sumber Power bergerak terhadap penerima ataupun sebaliknya (Tx dan Rx) Pengiri dan penerima.

Rumus Efek Doppler dapat dirumuskan dengan:

$\frac{F_{p}}{F_{s}}=\frac{V+V_{p}}{V+V_{s}}+V_{x}$ 
dimana:

fp adalah frekuensi yang didengar oleh penerima

fs adalah frekuensi yang dikeluarkan oleh sumber

$\mathrm{v}$ adalah kecepatan suara di Angin

vx adalah jumlah pengguna

vp adalah kecepatan penerima -jika bergerak-

vs adalah kecepatan sumber jika bergerak- .

\section{HASIL DAN PEMBAHASAN}

Analisa sistem merupakan proses memilah-milah suatu permasalahan menjadi elemen-elemen yang lebih kecil untuk dipelajari guna mempermudah pemecahan permasalahan dari suatu simulasi sistem monitoring, Hasil akhir dari proses analisis ini adalah menghasilkan laporan yang dapat menggambarkan sistem baru berjalan yang telah dipelajari dan masalah serta rancangan sistem baru atau usulan yang akan dikembangkan. Pada tahap analisis diperlukan suatu pendekatan analisis guna yaitu pada tahap simulasi dan perancangan, karena pada tahap ini merupakan tahapan yang paling penting. Pendekatan yang dilakukan adalah mendefinisikan setiap masalahpada sistem yang sedang berjalan dan sekaligus evaluasi terhadap sistem yang sedang berjalan tersebut dengan metode doppler, sehingga diperoleh suatu titik permasalahan dan diambil titik keputusan atas pemasalahan yang ada.

Tabel 1. Data Metro

\begin{tabular}{llllllll}
\hline \multirow{2}{*}{ NO } & \multirow{2}{*}{ Origin Me } & Destination Me & $\begin{array}{c}\text { TX Me } \\
\text { Sumber }\end{array}$ & $\begin{array}{c}\text { RX ME } \\
\text { Penerima }\end{array}$ & $\begin{array}{c}\text { Kecepatan } \\
\text { Angin }\end{array}$ & $\begin{array}{c}\text { Jumlah } \\
\text { Pengguna }\end{array}$ & Transmisi \\
\hline 1 & Jamin Ginting & To Cempaka & -10 & -2 & $2 \mathrm{Km} / \mathrm{Jam}$ & 7 & Radio Link \\
2 & Cempaka & To Komplek Astra & -11 & -5 & $2 \mathrm{Km} / \mathrm{Jam}$ & 7 & Radio Link \\
3 & Komplek Astra & To Jamin Ginting & -10 & -8 & $2 \mathrm{Km} / \mathrm{Jam}$ & 6 & Radio Link \\
\hline
\end{tabular}

\subsection{Penerapan Metode Doppler}

Secara umum, efek doppler dialami ketika ada suatu gerak relatif antara sumber dan penerima. Ketika sumber dan penerima bergerak saling mendekati, penerima frekuensi sinyal yang lebih tinggi dari pada frekuensi sinyal yang dipancarkan sumber tanpa adanya gerak relatif. Ketika sumber dan penerima bergerak saling menjauhi.

Lebih Efek Doppler, dinamakan mengikuti tokoh fisika, Christian Johann Doppler.

Berikut ini adalah rumus Doppler :

$\underline{F}_{p}=\underline{V+V_{p}}+V_{x}$

$\mathrm{F}_{\mathrm{s}} \quad \mathrm{V}+\mathrm{V}_{\mathrm{s}}$

Berikut ini ada Langkah-langkah Pengerjaan untuk menentukan bandwidht yang terpakai yaitu :

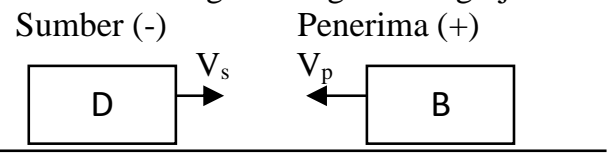

$\underline{F}_{p}=\underline{V+V_{p}}+V_{x}$

$\mathrm{F}_{\mathrm{s}} \quad \mathrm{V}-\mathrm{V}_{\mathrm{s}}$

1. (Jika Sumber dan penerima saling mendekati)

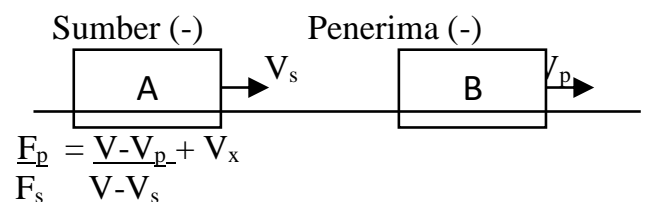

2. (Jika Sumber mendekati dan penerima menjauh)

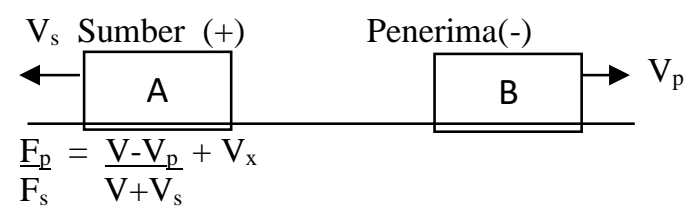

3. (Jika Sumber dan penerima saling menjahui)

Dalam kasusu ini ada 3 sampel kasus yang di gunakan sebagai uji coba metode doppler yaitu:

1. Jika sumber Jamin Ginting -10 saling mendekati cempaka -2 dengan kecepatan angin 2 km/jam dengan pengguna 7 orang, berapakah jumlah bandwitdh yang terpakai dan apakah statusnya ?

Penyelesain : 
Rumus : $\quad \underline{F}_{\mathrm{p}}=\underline{\mathrm{V}+\mathrm{V}_{\mathrm{p}}}+\mathrm{V}_{\mathrm{x}}$

$\mathrm{F}_{\mathrm{s}} \quad \mathrm{V}-\mathrm{V}_{\mathrm{s}}$

$\underline{\mathrm{F}}_{\mathrm{p}}=\frac{2+(-10)}{2-(-2)}+7=\underline{-8}+7=-2+7=5$

$\mathrm{F}_{\mathrm{s}} 2-(-2)$

Bandwidht yang terpakai dari jamin ginting saling mendekati bunga cempaka yang memakai 7 pengguna yaitu 5 mbps dan status working

2. Jika sumber Cempaka -11 mendekati Komplek Astra dan Komplek

Astra -5 menjauhi Jamin Ginting, kecepatan angin $2 \mathrm{~km} /$ jam dengan pengguna 7 orang, berapakah jumlah bandwitdh yang terpakai dan apakah statusnya ?

Penyelesain :

Rumus : $\quad \underline{F}_{p}=\underline{V-V_{p}}+V_{x}$

$\mathrm{F}_{\mathrm{S}} \quad \mathrm{V}-\mathrm{V}_{\mathrm{s}}$

$\underline{\mathrm{F}}_{\mathrm{p}}=\underline{1-(-11)}+8=\underline{12}+7=9$

$\mathrm{F}_{\mathrm{s}} 1-(-5)$

$\frac{12}{6}$

Bandwidht yang terpakai dari jamin ginting saling mendekati bunga cempaka yang memakai 7 pengguna yaitu 9 mbps dan status working

3. Jika sumber Cempaka -10 saling menjauhi Komplek Astra -6 dengan kecepatan angin 2 km/jam dengan pengguna 6 orang, berapakah jumlah bandwitdh yang terpakai dan apakah statusnya?

Penyelesain :

Rumus : $\quad \underline{F}_{p}=\underline{V-V_{p}}+V_{x}$

$\mathrm{F}_{\mathrm{S}} \quad \mathrm{V}+\mathrm{V}_{\mathrm{s}}$

$\underline{F}_{\mathrm{p}}=\underline{2-(-10)}+18=\underline{12}+6=3$

$\mathrm{F}_{\mathrm{S}} 2+(-6)$

$-4$

Bandwidht yang terpakai dari jamin ginting saling mendekati bunga cempaka yang memakai 6 pengguna yaitu 3 mbps dan status working

Tabel 2. Tabel Hasil Analisa Jumlah Bandwidht dan Status ME

\begin{tabular}{llllll}
\hline NO & Origin Me & Destination Me & Jumlah Bandwidht & Jumlah Pengguna & Status Me \\
\hline 1 & Jamin Ginting & To Cempaka & $5 \mathrm{Mb}$ & 7 & Working \\
2 & Cempaka & To Komplek Astra & $9 \mathrm{Mb}$ & 7 & Working \\
3 & Komplek Astra & To Jamin Ginting & $3 \mathrm{Mb}$ & 6 & Working \\
\hline
\end{tabular}

Adapun Bagan Monitoring Dan Simulasi Pengecekan Link ME dalam penelitian ini adalah sebagi berikut:

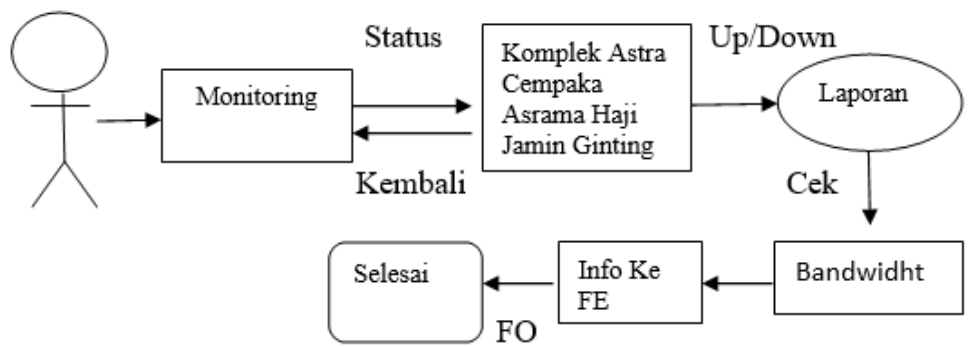

Gambar 1. Bagan Monitoring

Hasil monitoring User Akan mengetahui Status Link tersebut

Ket :

Cara - cara monitoring :

1. User Memonitoring Status Link ME Jamin Ginting - Cempaka - Asrama Haji

Dan Komplek Astra

2. Jika Suatu Link Down akan Maka User Membuat Laporan dan mengecek status bandwidht

3. User segera menginfokan ke Tim Fe Untuk segera melakukan pengecekannya

4. Jika ada problem Fo maka Tim Fe akan melakukan penyambungan 


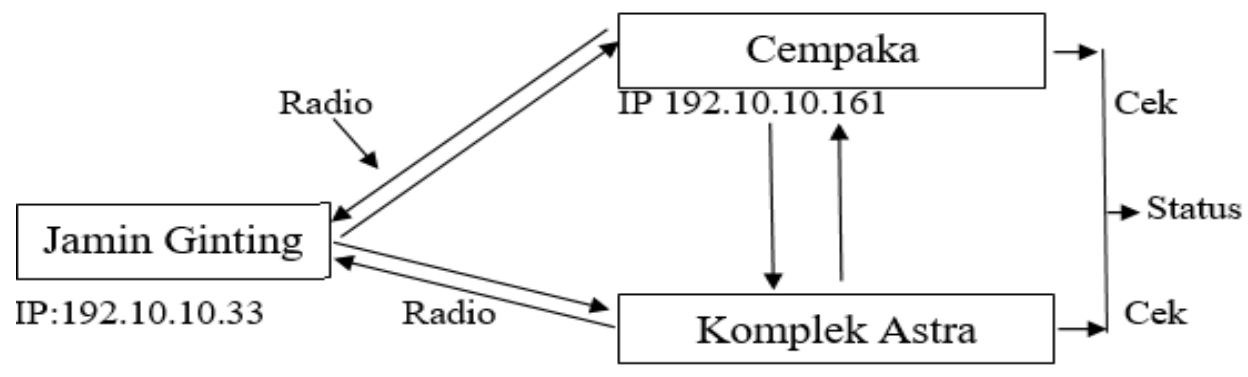

IP 192.10.10.29

Gambar 2. Simulasi ME

Keterangan :

1. ME Jamin Ginting - Cempaka : Menggunakan Transmisi Radio Link

2. ME Cempaka Komplek Astra : Menggunakan Transmisi Radio Link

3. ME Komplek Astra Jamin Ginting : Menggunakan Transmisi Radio Link

4. Software yang di gunakan menggunakan Packet Tracer

5. Metode yang di gunakan menggunakan Metode Doppler.

\subsection{Pengujian}

Dari hasil implementasi pengujian yanng dilakukan pada simulasi sistem Monitoring Link Metro Ethernet (ME) di PT Indosat Ooredoo Medan dengan metode Doppler adalah sebagiai berikut:

1. Tampilan Simulasi ME Jamin Ginting adalah Tampilan pada saat ME Jamin Ginting Terhubung ke pengguna.

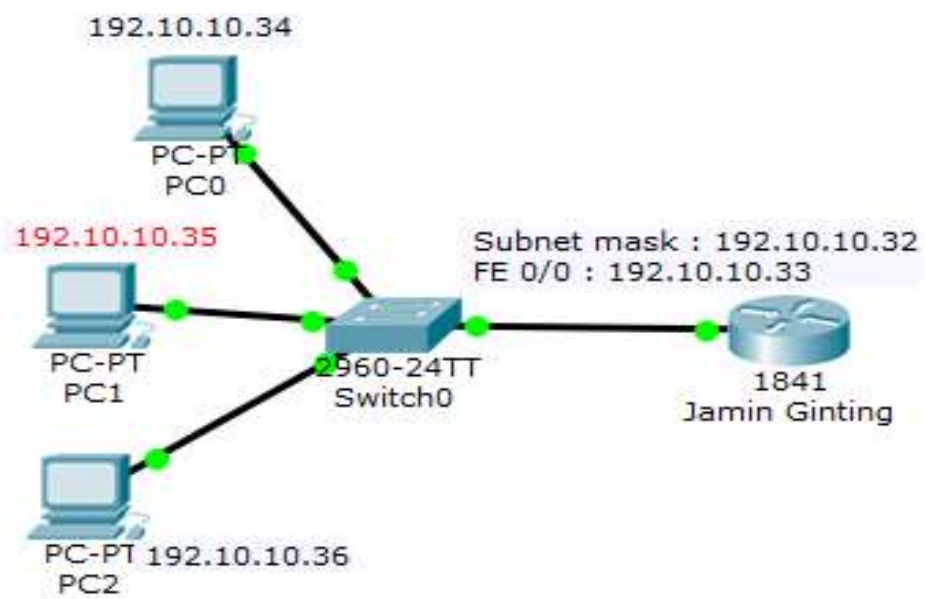

Gambar 3. ME Jamin Ginting

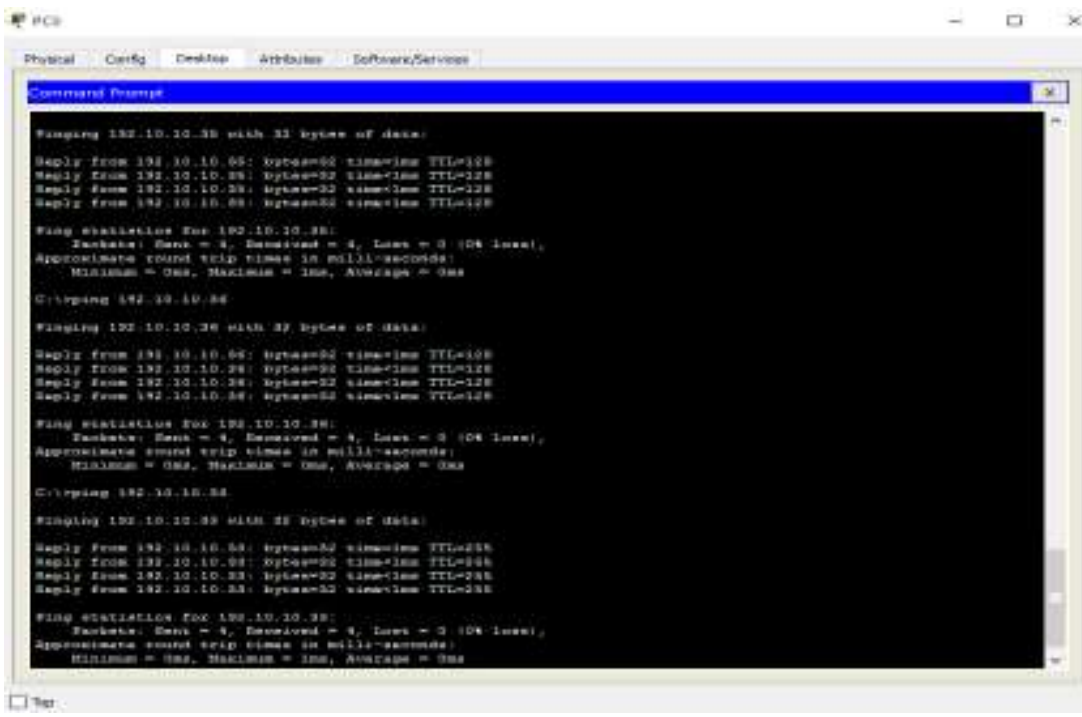

Gambar 4. Hasil Tes Ping Antar Komputer Pengguna di ME Jamin Ginting 
2. Tampilan Simulasi ME Jamin Ginting,Cempaka dan Komplek Astra adalah Tampilan pada saat ME Jamin Ginting Terhubung ke ME Komplek Astra dan Cempaka

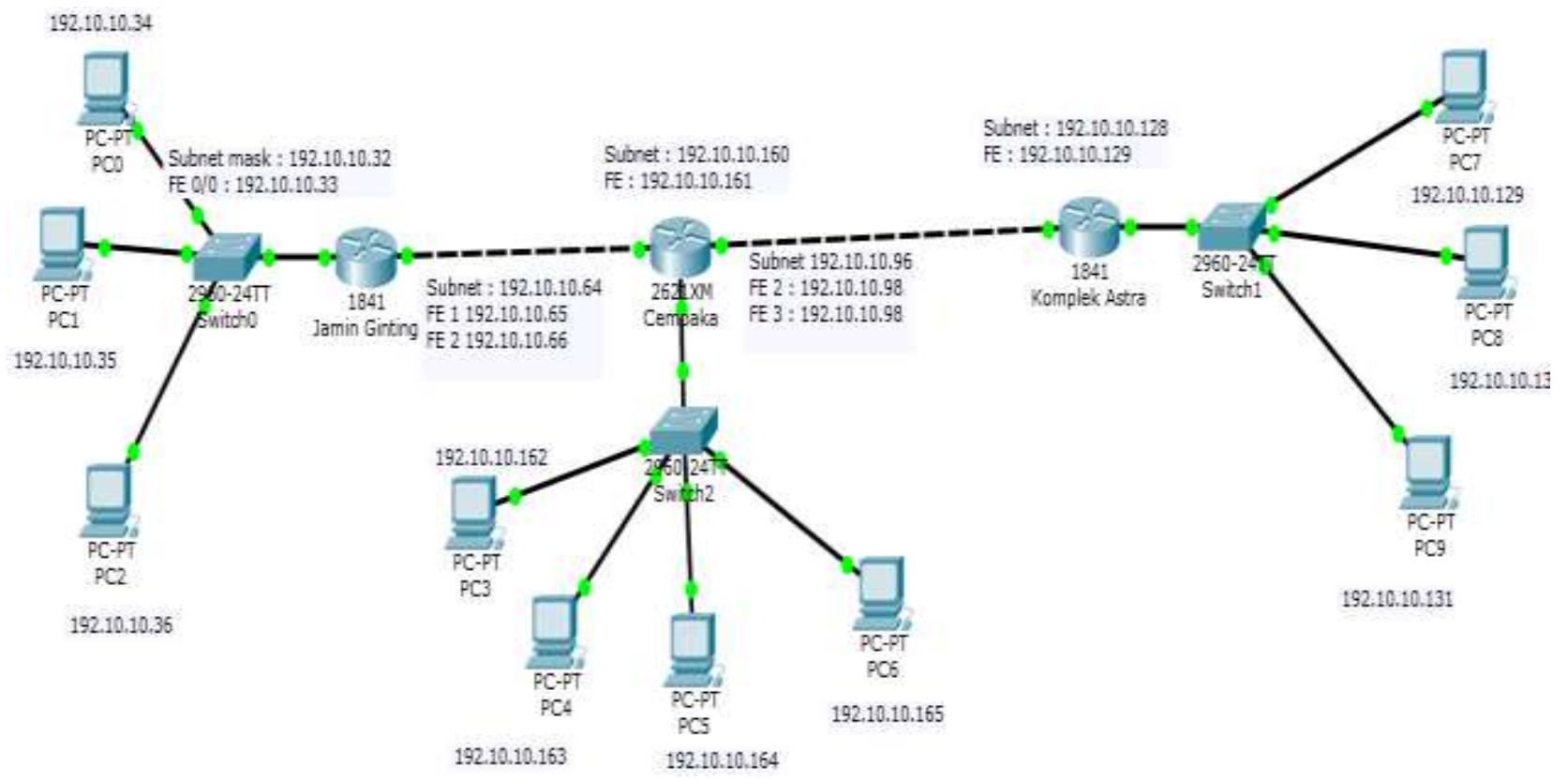

Gambar 5. Gambar Simulasi ME.

\section{KESIMPULAN}

Berdasarkan hasil analisayang dilakukan, maka kesimpulan dari penelitian simulasi sistem Monitoring Link Metro Ethernet (ME) di PT Indosat Ooredoo Medan dengan metode Doppler adalah sebagai berikut:

1. Penelitian ini telah berhasil menghasilkan proses monitroign link (ME) Metro Ethernet.

2. Berdasarkan hasil pengujian penelitian ini telah menerapkan proses monitoring Link ME dengan software packet Tracer.

\section{REFERENCES}

[1] Anggoro, Harry, 2009 Next Generation Network dengan Metro Ethernet 2009

[2] Sofana Iwan (2013), "CISCO CCNA" \& jaringan komputer. ( Edisi Revisi)." Bandung Informatika

[3] Kristanto, Andi (2007) Perancanaan Sistem informasi dan aplikasi Yogyakarta : Gava Media.

[4] Jogiyanto, HM 2005, Analisis dan Desain Sistem Informasi, Andi Offset, Yogyakarta

[5] Moeediyanto, 2009, Teknik Monitoring dan Evaluasi (monev) dalam rangka memperoleh informasi dan pengambilan keputusan menagemen, Yogyakarta

[6] Utorodewo, Fecelia N, Bahasa Indonesia Jakarta : Universitas Indonesia ,2007 